\title{
PENGARUH KEPRIBADIAN PROAKTIF, COMMUNICATION SKILLS, FAMILY RESPONSIBILITIES TERHADAP KESUKSESAN KARIR
}

\author{
Nurdian Susilowati, Amir Mahmud, Satsya Yoga Baswara, Husnul Khuluq \\ Universitas Negeri Semarang, Indonesia \\ nurdiansusilowati@mail.unnes.ac.id,amirmahmud@mail.unnes.ac.id,satsya.yoga@mail.unnes.ac.id, \\ husnulkhuluq60@students.unnes.ac.id
}

\begin{abstract}
Abstrak: Penelitian ini bertujuan untuk mengetahui pengaruh kepribadian proaktif, keterampilan komunikasi, tanggung jawab keluarga terhadap keberhasilan karir. Sampel penelitian 158 lulusan pendidikan akuntansi. Teknik pengumpulan data menggunakan kuesioner. Data yang sudah terkumpul kemudian dianalisis menggunakan regresi berganda. Hasil penelitian menunjukkan bahwa kepribadian proaktif, keterampilan komunikasi, dan tanggung jawab keluarga berpengaruh signifikan terhadap keberhasilan karir. Individu yang memiliki kepribadian proaktif mampu memindai peluang, menunjukan inisiatif, mengambil tindakan, dan bertahan sampai mereka mencapai akhir dengan membawa perubahan Komunikasiyang dilakukan dalam aktivitas keseharian merupakan modal dan kunci sukses dalam pergaulan serta jenjang karier, karena melalui komunikasi suatu hubungan baik dapat dibangun dan dibina. Tanggung jawab dalam sebuah keluarga dapat berpengaruh pada kesuksesan karir seseorang. Untuk mencapai kesuksesan tersebut, peran keluarga dalam memberikan dukungan sangat dibutuhkan
\end{abstract}

Kata kunci: Kesuksesan Karir, Kepribadian Proaktif, Keterampilan Komunikasi, Tanggung Jawab Keluarga

\section{THE EFFECT OF PROACTIVE PERSONALITY, COMMUNICATION SKILLS, FAMILY RESPONSIBILITIES ON CAREER SUCCESS}

\begin{abstract}
This study aims to determine the effect of proactive personality, communication skills, and family responsibility on career success. The research sample was 158 accounting education graduates. The data collection technique used a questionnaire. Data were collected and analyzed using multiple regression. The results showed that proactive personality, communication skills, and family responsibilities significantly affected career success. Individuals who have a proactive personality can scan for opportunities, show initiative, take action, and survive until they reach the end by bringing about change. Communication in daily activities is an asset and the key to success in relationships and the career ladder because through communication; a good relationship can be built and fostered. Responsibilities in a family can affect a person's career success. To achieve this success, the role of the family in providing support is needed.
\end{abstract}

Keywords: Career Success, Proactive Personality, Communication Skills, Family Responsibilities

\section{PENDAHULUAN}

Kesuksesan karir menjadi perhatian penting dan populer dalam berbagai bidang penelitian (Adiyono, 2017). Kesuksesan karir merupakan keberhasilan atau prestasi yang nyata dirasakan oleh individu sebagai akumulasi hasil dari pengalaman kerja mereka. kesuksesan karir digambarkan sebagai kondisi psikologi positif atau hasil dari pekerjaan atau prestasi pribadi dan pencapaian profesional yang diperoleh dari pengalaman kerja. Tidak semua individu bisa memperoleh kesuksesan karir. Kesuksesan karir mengandung dua makna, yaitu kesuksesan karir secara obyektif dan kesuksesan karir secara subyektif dengan kata lain kesuksesan karir dapat dijelaskan dalam dua komponen utama yaitu komponen obyektif dan subyektif (Talib et al., 2015). 
Pilihan karir lulusan Pendidikan Akuntansi sangat beragam. Berdasarkan data penelusuran alumni tahun 2020, lulusan Pendidikan Akuntansi memilih karir menjadi guru akuntansi, guru ekonomi, guru kewirausahaan, akuntan perusahaan, akuntan pemerintah, maupun wirausaha. Banyak kendala dalam pencapaian kesuksesan karir. Diantaranya mereka masih menjadi guru honorer, sehingga jenjang karir tidak jelas. Begitu juga yang menjadi wirausaha mendapatkan persaingan yang sangat kompetitif dari perusahaan yang menghasilkan produk sejenis. Oleh karena itu perlu memiliki kemampuan adaptasi yang memadai (Majid et al., 2012).

Kepribadian proaktif menjadi salah satu penentu bagi kesuksesan karir seseorang (Joo \& Ready, 2012). Kepribadian proaktif dapat menjelaskan adaptabilitas karier individu (Akmal, 2019). Hasil penelitian lainnya juga menjelaskan kepribadian proaktif memliki pengaruh terhadap kesuksesan karir (majid et al 2020). Kepribadian proaktif sebagai kepribadian yang relatif tidak dibatasi oleh kekuatan situasional dan yang mempengaruhi perubahan lingkungan (Fee, Kirana, Zubaidah, \& Pangil, 2013). Individu yang memiliki karakteristik kepribadian proaktif dapat mengubah lingkungannya agar sesuai dengan dirinya dan kebutuhannya, sehingga individu yang proaktif akan lebih siap dalam mengatasi permasalahan karier terutama pada masa transisi dibandingkan dengan individu yang tidak memiliki karakteristik kepribadian proaktif. Aspekaspek kepribadian proaktif diantarnya yaitu kemampuan mengidentifikasi peluang, inisiatif, responsif, dan adanya perubahan (Mayrhofer et al., 2007). Hubungan kepribdian proaktif dengan kesukesan karir dapat djelaskan dengan teori behavioral Krumboltz, bahwa faktor ini dibawa dari lahir berupa wujud, keadaan fisik dan kemampuan (Garkaz et al., 2011).

Selanjutnya, keterampilan komunikasi (communication skills) juga berpengaruh terhadap kesuksesan karir. Communication skills merupakan keterampilan yang penting untuk dipelajari sehingga dapat berkomunikasi dengan lancar. Baik dengan atasan maupun dengan bawahan dan sesama kolega kantor (Ahmed Atef Oussi, 2017). Penelitian lainnya juga menghasilkan temuan bahwa communication skills mendukung peningkatan karir individu (Majid et al., 2012). Keterampilan komunikasi terbagi menjadi tiga macam yaitu keterampilan komunikasi lisan, keterampilan komunikasi tulisan, dan keterampilan komunikasi visual. Keterampilan komunikasi lisan (oral communication skill) merupakan kemampuan seseorang dalam berkomunikasi melalui berbicara dan umpan balik (feedback) dapat diberikan secara langsung. Keterampilan komunikasi lisan meliputi kemampuan dalam wawancara kerja, seminar, lokakarya, public speaking, pidato formal dan presentasi (Ahmed Atef Oussi, 2017). Keterampilan komunikasi tulisan (written communication skill) merupakan kemampuan seseorang membuat pesan-pesan secara tertulis dalam berbagai macam bentuk, seperti memo, surat, proposal, dan laporan. Keterampilan komunikasi visual merupakan kemampuan seseorang dalam mengkomunikasikan pesan atau informasi kepada pembaca dengan menggunakan media visual, seperti tipografi, ilustrasi, warna, garis, dan lain sebagainya dengan bantuan teknologi. Menurut (Jones, 2011) Keterampilan komunikasi adalah kompetensi pribadi yang mendasar untuk kesuskesan karir akuntansi. Keterampilan komunikasi dainggap sebagai bakat paling penting bagi lulusan untuk cepat mendapatkan akses ke karir yang diharapkan.

Tanggung jawab keluarga berpengaruh penting terhadap pekerjaan. Menurut (Tharenou, Latimer, \& Conroy, 1994) telah ditemukan bahwa kedudukan keluarga memainkan peran sentral dalam pengalaman kerja individu. Sumber daya seperti waktu, perhatian dan energi, terbatas, dan yang dihabiskan dalam satu domain tidak tersedia untuk domain lain. Tanggung jawab dalam sebuah keluarga dapat berpengaruh pada kesuksesan karir seseorang. Untuk mencapai kesuksesan tersebut, peran keluarga dalam memberikan dukungan sangat dibutuhkan (Umar, 2017). Dukungan tersebut dapat berupa dukungan emosional, informatif, evaluatif, dan instrumental. Pentingnya keluarga untuk individu dan tingkat investasi psikologis dalam keluarga biasanya 
disebut sebagai keterlibatan keluarga. Mirip dengan keterlibatan kerja, keterlibatan keluarga diyakini menciptakan tekanan internal untuk menginvestasikan peningkatan upaya dan energi dalam domain keluarga untuk memenuhi tuntutan peran keluarga (Parasuraman \& Simmers, 2001). Penelitian (Hayfaa Tlaiss, 2011) menunjukan bahwa family responsibility berpengaruh terhadap the career advancement of Lebanese women managers. Tanggung jawab keluarga mempengaruhi kinerja karyawan pada pekerjaannya yang dapat mengarah pada kesuksesan karier individu (Al-balam, 2009). Artinya, tanggungjawab keluarga dapat membentuk kesuksesan karir individu.

Penelitian ini memberikan kontribusi pada teori pengembangan karir yang menjelaskan bahwa individu melalui beberapa tahapan karir dan adaptabilitasnya pada karir yang saat ini dijalankan. Lulusan Pendidikan Akuntansi dengan beberapa pilihan karir yang dapat ditekuni memberikan alternatif pilihan karir yang dapat mereka tuju. Akhirnya ketika mereka memilih salah satu pilihan tersebut maka perlu merencanakan tahapan perencanaan karir sehingga mencapai kesuksesan karir. Tujuan penelitian ini adalah menjelaskan pengaruh kepribadian proaktif, communication skills, dan family responsibility pada kesuksesan karir. Sehingga dapat diketahui variabel yang memberikan peranan yang tinggi.

\section{METODE}

Penelitian ini merupakan jenis penelitan kuantitatif dengan pendekatan kausalitas. Pendekatan kausalitas menguji variable bebas terhadap variable terikat. Populasi dalam penelitian ini adalah lulusan Pendidikan Akuntansi sejumlah 430 orang. Data tersebut berasal dari data penelusuran alumni. Pengambilan sampel atas responden dilakukan secara probability sampling (sampel acak) dengan metode simple random sampling, sehingga diperoleh sampel sebanyak 158 responden.

Variabel penelitian ini terdiri dari tiga variabel bebas dan satu variabel terikat. Variabel bebasnya yaitu kepribadian proaktif, communication skills, dan family responsibilities. Sedangkan variabel terikatnya adalah kesuksesan karir. Kesuksesan karir didefinisikan sebagai keberhasilan atau prestasi yang nyata dirasakan oleh individu sebagai akumulasi hasil dari pengalaman kerja mereka. indikator kesuksesan karir yaitu gaji atau pendapatan, kekuasaan atau jumlah promosi, dan status pekerjaan. Kepribadian proaktif adalah inisiatif untuk membuat perubahan positif dalam lingkungan pekerjaannya dengan mengatasi hambatan, meningkatkan kinerja, dan membuat hal yang baru. Indikator kepribadian proaktif yaitu kemampuan mengidentifikasi peluang, menunjukan inisiatif, mengambil tindakan, bertahan dalam pekerjaan, dan membawa perubahan. Ketrampilan komunikasi merupakan kemampuan individu dalam menyampaikan pendapat ataupun gagasan secara lisan dan tertulis. Indikator Keterampilan komunikasi keterampilan komunikasi lisan, keterampilan komunikasi tulisan, dan keterampilan komunikasi visual. Family responsibilities mengacu pada dukungan keluarga baik secara emosional, informatif, evaluatif, dan instrumental. Pentingnya keluarga untuk individu dan tingkat investasi psikologis dalam keluarga biasanya disebut sebagai keterlibatan keluarga. indikator family responsibilities yaitu peduli, dukungan emosional, menceritakan masalah, dan membantu dalam membuat keputusan.

Teknik pengumpulan data yang dipakai adalah kuesioner. Sejumlah 158 responden mengisi kuesioner menggunakan google form. Pengembangan kuesioner atau instrumen penelitian dilakukan dengan mengacu pada penelitian terdahulu dan menggunakan skala likert. Jenis datanya adalah data primer. Data yang sudah terkumpul kemudian dianalisis menggunakan analisis statistik inferensial regresi berganda. Sebelum menggunakan analisis regresi linier berganda, terlebih dahuludilakukan uji validitas dan reliabilitas. Selanjutnya melakukan uji prasarat regresi berganda yaitu uji asumsi klasik. 


\section{HASIL DAN PEMBAHASAN}

Sebelum dilakukan uji regresi berganda, maka dilakukan uji validitas dan reliabilitas data. Berdasarkan hasil analisis data diperoleh bahwa valid dan reliabel. Selanjtunya dilakukan uji asumsi klasik. Uji Normalitas, Rasio skewness dan rasio kurtois dalam penelitian ini dijadikan sebagai petunjuk apakah suatu data berdistribusi normal atau tidak. Rasio skewness sendiri merupakan nilai skewness dibagi dengan standar eror skewness, sedangkan rasio kurtois adalah nilai kurtosis dibagi dengan standard error kurtosis. Sebagai pedoman, bila rasio kurtosis dan skewness berada diantara -2 hingga $=2$, maka distribusi adalah norma (Santoso 2000). Terlihat bahwa rasio skewness $=-0,602 / 0.254=2,370$ : sedangkan rasio kurtosis $=0,687 / 0.503=1,365$. Karena rasio skewness dan rasio kurtosis berada diantara -2 hingga +2 , maka dapat disimpulkan bahwa distribusi data adalah normal. Terlihat bahwa nilai tolerance tidak ada yang kurang dari 0,10 . Variabel kepribadian proaktif memiliki tolerance 0.688 , Communications skills sebesar 0.711, dan Famil responsibilities sebesar 0.629. hal tersebut berarti tidak ada korela variabel independen/ bebas. Hasil perhitungan VIF juga menunjukkan tidak ada variabel yang memiliki VIF lebih dari 10. Kepribadian proaktif sebesar 1.453, communications skills sebesar 1.406, dan family responsibilities sebesar 1.589. sehingga dapat disimpulkan bahwa tidak ada multikorelasi antar variabel independen/bebas dalam model regresi.

Dari hasil Uji $\mathrm{F}$ pada penelitian ini didapatkan nilai $\mathrm{F}$ hitung sebesar 80,145 dengan angka signifikansi (P value) sbesar 0,000. Dengan tingkat signifikansi 95\% $(\alpha=0,05)$. Angka signifikansi ( $\mathrm{P}$ value) sebesar $0,000<0,05$. Atas dasar perbandingan tersebut, maka $\mathrm{H}_{0}$ ditolak artinya kepribadian proaktif, communication skills, dan family responsibilites mempunyai pengaruh signifikan secara bersama-sama tehadap kesuksesan karir. Berikut tabel hasil analysis menggunakan Uji F.

Tabel 1. Hasil Uji ANOVA ${ }^{a}$ (Uji F)

\begin{tabular}{cccccc}
\hline Model & Sum of Squares & df & Mean Square & F & Sig. \\
\hline Regression & 312.460 & 3 & 104.153 & 80.145 & $.000^{\mathrm{b}}$ \\
Residual & 111.762 & 86 & 1.300 & & \\
Total & 424.222 & 89 & & & \\
\hline
\end{tabular}

a. Dependent Variable: KESUKSESAN KARIR

b. Predictors: (Constant), FAMILY, CSkill, Kproaktif

Selanjutnya, uji statistik t menunjukkan seberapa jauh pengaruh satu variabel bebas secara parsial dalam menerangkan variasi variabel terikat. Dalam penelitian ini menggunakan signifikansi level $0,05(\alpha=5 \%)$ untuk kepribadian proaktif, communication skills, family responsibilities. Jika t-hitung $<\mathrm{t}$-tabel, maka variabel independen secara parsial tidak berpengaruh terhadap variabel dependen (hipotesis ditolak). Sedangkan Jika t-hitung $>\mathrm{t}$-tabel maka variabel bebas secara parsial berpengaruh terhadap variabel terikat (hipotesis diterima). Dalam penelitian ini, nilai $t$ tabel sebesar 1,98793 . Hipotesis pertama $\mathrm{H}_{1}$ berbunyi ada pengaruh kepribadian proaktif terhadap kesuksesan karir diterima. Berdasarkan hasil penelitian, variabel kepribadian proaktif mempunyai t-hitung 2,952 lebih besar dari t-tabel 1,987. Disamping itu juga adiperoleh nilai signifikansi 0.004 lebih kecil dari taraf signifikansi 0,05. Dapat disimpulkan bahwa kepribadian proaktif berpengaruh terhadap kesuksesan karir.

Hipotesis kedua $\mathrm{H}_{2}$ communication skills berpengaruh terhadap kesuksesan karir diterima. Berdasarkan hasil penelitian communication skills mempunyai t-hitung 9,665 lebih besar dari ttabel 1,987. Nilai signifikansi 0.000 lebih kecil dari taraf signifikansi 0,05. Dapat disimpulkan 
bahwa variabel communication skills berpengaruh terhadap kesuksesan karir. Hipotesis ketiga $\mathrm{H}_{3}$ yang berbunyi ada pengaruh family responsibilities terhadap kesuksesan karir. Diterima. Hasil penelitian menunjukkan bahwa family responsibilities mempunyai t-hitung 2.630 lebih besar dari t-tabel 1,987.

Nilai signifikansi 0.010 lebih kecil dari tarf signifikansi 0,05. Dapat disimpulkan bahwa family responsibilities berpengaruh terhadap kesuksesan karir. Berikut tabel hasil analisis regresi.

Tabel 2. Hasil Regresi Berganda

\begin{tabular}{ccccccc}
\hline Model & \multicolumn{2}{c}{$\begin{array}{c}\text { Unstandardized } \\
\text { Coefficients }\end{array}$} & \multicolumn{2}{c}{$\begin{array}{c}\text { Standardized } \\
\text { Coefficients }\end{array}$} & Sig. \\
& B & Std. Error & Beta & t & & \\
\hline Constant & -2.807 & 2.346 & & -1.196 & .235 & \\
KProaktif & .146 & .049 & .197 & 2.952 & .004 & \\
Cskill & .876 & .091 & .634 & 9.665 & .000 & \\
Family & .138 & .052 & .183 & 2.630 & .010 & .629 \\
\hline Dependent variable: Kesuksesan Karir & & & & &
\end{tabular}

Hasil statistik deskriptif menunjukkan bahwa ketiga variabel independen memiliki standar deviasi yang tidak tinggi karena nilai standar deviasi tidak melebihi nilai rata-ratanya (mean). Semakin tinggi nilai standar deviasi berarti semakin tinggi penyimpangan data dengan nilai rataratanya. Sebaliknya, semakin kecil nilai standar deviasinya berarti data berkelompok disekitar nilai rata-ratanya dan tidak menunjukan variasi yang banyak (Joo \& Ready, 2012).

Hasil penelitian ini didukung dari penelitian (Aristovnik et al., 2017) yang mengatakan bahwa kepribadian proaktif berpengaruh pada positif dan signifikan terhadap adaptabilitas karir. Kepribadian proaktif sebagai kepribadian yang relatif tidak dibatasi oleh kekuatan situasional dan yang mempengaruhi perubahan lingkungan. Individu yang memiliki karakteristik kepribadian proaktif dapat mengubah lingkungannya agar sesuai dengan dirinya dan kebutuhannya, sehingga individu yang proaktif akan lebih siap dalam mengatasi permasalahan karier terutama pada masa transisi dibandingkan dengan individu yang tidak memiliki karakteristik kepribadian proaktif (Asif et al., 2020; Gunarathne, 2019; Siemens et al., 2013). Dalam hal ini, kepribadian proaktif akan mempengaruhi perubahan lingkungan dan mampu mellihat peluang masa depan untuk kesuksesan karir.

Sesuai dengan hasil penelitian yang dilakukan oleh (Joo \& Ready, 2012) yang menyatakan bahwa keterampilan komunikasi tertulis maupun lisan sangat penting dimiliki lulusan dalam memasuki dunia kerja. Keterampilan melakukan komunikasi yang efektif akan berperan besar dalam mendukung pencapaian tujuan dari seluruh aktivitas (Viviers et al., 2016). Untuk dapat melakukan komunikasi yang efektif, maka kemampuan untuk mengirimkan pesan atau informasi yang baik, dan kemampuan untuk menjadi pendengar yang baik, merupakan bagian yang sangat penting (Akmal, 2019) keterampilan komunikasi sebagai bakat paling penting yang diperlukan untuk sukses berkarir di bidang akuntansi (Putri \& Nrh, 2015)

Family responsibility berupa dukungan sosial keluarga dan efikasi diri secara bersama-sama berperan positif dan signifikan dalam meningkatkan work-life balance (Ayu et al., 2019). individu yang memiliki dukungan sosial yang baik memiliki rasa percaya diri yang baik dalam 
menyelesaikan tugas yang dihadapi, mengurangi stres dan mencegah timbulnya depresi (Friedman 2009). Kemampuan dalam menyelesaikan tugas dengan baik merupakan sebuah syarat yang harus dipenuhi ketika seseorang berada dalam lingkungan kerja. Individu dengan dukungan sosial keluarga yang rendah akan menimbulkan efek negatif seperti stres dan kemampuan resiliensi yang rendah terhadap suatu masalah (Hayfaa Tlaiss, 2011). Menjalani peran yang berlebih atau roleoverload menyebabkan bertambahnya beban dan tanggung jawab yang dimiliki oleh individu. Individu yang memasuki usia remaja khususnya remaja akhir akan lebih mendengarkan informasi dan nasehat yang diberikan oleh teman sebaya dibanding keluarga sehingga diperlukan komunikasi yang efektif serta pola asuh yang baik seperti otoritatif agar orangtua mampu menyalurkan dukungan untuk membantu menyeimbangkan kehidupan remaja (Mayrhofer et al., 2007). Lingkungan kerja dan dukungan sosial mampu memberikan energi positif dalam menyeimbangkan kehidupan dan kesejahteraan secara psikologis. kedudukan keluarga memainkan peran sentral dalam pengalaman kerja individu. Tanggung jawab dalam sebuah keluarga dapat berpengaruh pada kesuksesan karir seseorang.

Penelitian ini sejalan dengan teori pengambilan keputusan karir Behavioral dengan model (Krumboltz 1979) bahwa kepribadian proaktif berpengaruh kesuksesan karir. Cara seseorang membuat keputusan karir ditentukan oleh faktor-faktor pribadi dan lingkungan. dengan Faktor pribadi berkenaan dengan apa yang sudah ada pada diri seseorang seperti jenis kelamin, tampakan fisik, dan kemampuan-kemampuan yang mengandung unsur bawaan (Chen, 2003). Ada empat kategori faktor yang mempengaruhi pengambilan keputusan karir yaitu faktor genetik, lingkungan, belajar, dan keterampilan menghadapi tugas atau masalah. Menurut teori belajar, dalam pengambilan keputusan karir orang berada di lingkungan tertentu, dengan membawa ciriciri bawaan dari keturunannya dan menghadapi berbagai pengalaman belajar (Ahmed Atef Oussi, 2017) Orang memang tidak bisa mengatur sifat bawaannya, tetapi dapat mempengaruhi lingkungan dan pengalaman belajarnya.

\section{SIMPULAN}

Kepribadian proaktif berpengaruh terhadap kesuksesan karir, hal ini menunjukkan bahwa semakin tinggi kepribadian proaktif maka akan semakin berpengaruh terhadap kesuksesan karir. Artinya individu mampu membuat perubahan positif dalam lingkungan pekerjaannya dengan mengatasi hambatan, meningkatkan kinerja, dan membuat hal yang baru. Communication skills berpengaruh positif dan signifikan terhadap kesuksesan karir. hal ini menunjukkan bahwa semakin tinggi kemampuan communication skills maka akan semakin berpengaruh terhadap kesuksesan karir. Individu dapat melakukan komunikasi lisan, tulisan, dan visual dengan baik sehingga pesan yang disampaikan dapat dipahami. Family responsibilities mengacu pada dukungan keluarga baik secara emosional, informatif, evaluatif, dan instrumental. Pentingnya keluarga untuk individu dan tingkat investasi psikologis dalam keluarga biasanya disebut sebagai keterlibatan keluarga. indikator family responsibilities yaitu peduli, dukungan emosional, menceritakan masalah, dan membantu dalam membuat keputusan. Family responsibilities berpengaruh positif dan signifikan terhadap kesuksesan karir. Hal ini menunjukkan bahwa semakin semakin tinggi dukungan keluarga akan berpengaruh terhadap kesuksesan karir.

Penelitian ini memberikan implikasi pada perkembangan teori karir. Individu membuat perencanaan karir berdasarkan pilihan karir yang ada. Dalam perencanaan karir diperlukan persiapan yang matang sehingga dapat mencapai kesuksesan karir. Sebagian besar individu 
mengalami kegagalan karir karena tidak ada perencanaan karir yang matang. Saran bagi peneliti selanjutnya adalah dapat meneliti personality trait dalam menunjang kesuksesan karir.

\section{DAFTAR PUSTAKA}

Adiyono, R. purnomo. (2017). pengaruh kepribadian lima faktor terhadap kesuksesan karir. Jurnal Bisnis Dan Ekonomi, 24(2), 162-176.

Ahmed Atef Oussi, M. F. K. (2017). Article information: Accounting students ' perceptions of important business communication skills: An exploratory study in the Tunisian context. Journal of Financial Reporting and Accounting, 15(2). https://doi.org/10.1108/JFRA-10-20150092

Akmal, F. U. S. Z. (2019). PERAN KEPRIBADIAN PROAKTIF TERHADAP ADAPTABILITAS KARIER PADA MAHASISWA TINGKAT AKHIR. Psikologi Ilmiah, $11(1), 45-54$.

Al-balam, N. M. (2009). Impact of family responsibilities on career success among employees working in the semi-government sector in the state of Qatar Syed Asif Raza *. 1(2), 208-223.

Aristovnik, A., Tomazevic, N., Kerzic, D., \& Umek, L. (2017). The impact of demographic factors on selected aspects of e-learning in higher education. International Journal of Information and Learning Technology, 34(2), 114-121. https://doi.org/10.1108/IJILT-09-2016-0045

Asif, M., Thomas, G., Awan, M. U., \& Muhammad Din, A. (2020). Enhancing student engagement through heterogeneous pedagogical approaches: action research in a university level course in Saudi Arabia. International Journal of Educational Management, 35(1), 1-28. https://doi.org/10.1108/IJEM-10-2019-0375

Ayu, D., Triwijayanti, K., \& Astiti, P. (2019). Peran Dukungan Sosial Keluarga dan Efikasi Diri Terhadap Tingkat Work-Life Balance Pada Mahasiswa Yang Bekerja Di Denpasar. 6(2), 320-327.

Chen, C. P. (2003). Integrating perspectives in career development theory and practice. Career Development Quarterly, 51(3), 203-216. https://doi.org/10.1002/j.2161-0045.2003.tb00602.x

Garkaz, M., Banimahd, B., \& Esmaeili, H. (2011). Factors Affecting Accounting Students' Perf ormance: The Case Of Students At The Islamic Azad University. Procedia - Social and Behavioral Sciences, 29, 122-128. https://doi.org/10.1016/j.sbspro.2011.11.216

Gunarathne, N. (2019). Outcome-based education in accounting The case of an accountancy degree. https://doi.org/10.1108/JEAS-08-2018-0093

Hayfaa Tlaiss, S. K. (2011). The impact of gender, family , and work on the career advancement of Lebanese women managers. An International Journal, 26(1). https://doi.org/10.1108/17542411111109291

Joo, B. B., \& Ready, K. J. (2012). Career satisfaction The influences of proactive personality ,. https://doi.org/10.1108/13620431211241090

Lukito, C. D. R. (2020). Determinasi kepribadian proaktif terhadap kesuksesan karir melalui leader member exchange. 8, 265-275.

Majid, S., Liming, Z., Tong, S., \& Raihana, S. (2012). Importance of Soft Skills for Education and Career Success. 2(2), 1036-1042.

Mayrhofer, W., Meyer, M., Schiffinger, M., \& Schmidt, A. (2007). The influence of family responsibilities, career fields and gender on career success An empirical study. 292-323. https://doi.org/10.1108/02683940810861392

Putri, A. R., \& Nrh, F. (2015). Self Esteem Dan Optimisme Raih Kesuksesan Karir Pada Fresh Graduate Fakultas Teknik Universitas Diponegoro. Empati, 4(4), 15-19.

Siemens, L., Althaus, C., \& Stange, C. (2013). Balancing students' privacy concerns while increasing student engagement in e-learning environments. In Cutting-Edge Technologies in Higher Education (Vol. 6, Issue PARTG). Emerald Group Publishing Limited. https://doi.org/10.1108/S2044-9968(2013)000006G014

Talib, J. A., Salleh, A., Amat, S., Ghavifekr, S., \& Ariff, A. M. (2015). Effect of career education module on career development of community college students. International Journal for Educational and Vocational Guidance, 15(1), 37-55. https://doi.org/10.1007/s10775-014-9279$\mathrm{X}$

Umar, I. (2017). Factors Influencing Students 'Career Choice in Accounting: The Case of Yobe Factors 
Jurnal Ekonomi \& Pendidikan, 18(1), 2021

Influencing Students 'Career Choice in Accounting : The Case of Yobe State University. January 2014.

Viviers, H. A., Fouché, J. P., \& Reitsma, G. M. (2016). Developing soft skills (also known as pervasive skills) Usefulness of an educational game. Meditari Accountancy Research, 24(3), 368389. https://doi.org/10.1108/MEDAR-07-2015-0045 